\title{
ELEIÇÕES MUNICIPAIS 2012 E 2016 E A SUB- REPRESENTAÇÃO FEMININA: A INFLUÊNCIA DE FATORES POLÍTICO-INSTITUCIONAIS
}

\author{
Female Underrepresentation in the Municipal Elections of 2012 and 2016: the \\ influence of political and institutional factors
}

(iD) Alan da Silva Pereira

(iD) Carlos Augusto da Silva Souza

(iD) Cloves Luiz Pereira Oliveira

Resumo: Este artigo apresenta como objeto de investigação a eleição de mulheres para as Câmaras Municipais, partindo da evidência que as mulheres estão sub-representadas em cargos legislativos. Especificamente, a pesquisa procurou relacionar a dificuldade das mulheres em acessar as arenas decisórias a partir de duas variáveis constantes da literatura: a magnitude dos distritos e a ideologia partidária. A partir da utilização de uma metodologia de correlação, o teste das hipóteses indicou que a magnitude não apresenta capacidade explicativa suficiente para explicar a baixa eleição de mulheres no território brasileiro. Por outro lado, o estudo procurou verificar a relação entre a eleição de mulheres e as diferenças ideológicas entre as agremiações partidárias, no entanto, os resultados apresentados não encontraram grandes variações nas eleições de mulheres em relação à dimensão ideológica das candidaturas.

Palavras-chave: Mulher e política. Sub-representação feminina. Eleições municipais.

\begin{abstract}
This article presents the election of women to City Councils as an object of investigation, based on evidence that women are underrepresented in legislative positions. Specifically, the research relates the difficulty of women accessing decision-making arenas based on two variables in the literature: district size and party ideology. Using a correlation methodology, the hypothesis test indicated that district size does not sufficiently explain why few women are elected in Brazil. The study aimed to verify the relationship between the election of women and the ideological differences between the parties. The results did not show great variation in the election of women regarding party ideology. Keywords: Women and politics. Female underrepresentation. Local elections.
\end{abstract}

Artigo recebido em 1 dez. 2020 e aprovado em 1 jul. 2021

Editor responsável: Luiz Magno Pinto Bastos Junior

DOI: https://doi.org/10.53323/resenhaeleitoral.v25i1.128 


\section{Introdução}

A sub-representação das mulheres na esfera política é, hoje, entendida como um grande problema dos governos democráticos. A diferença entre o universo de mulheres presentes na pirâmide demográfica e o percentual de mulheres presentes em cargos eletivos gera um problema na qualidade da Democracia Representativa.

Segundo projeção populacional realizada pelo Instituto Brasileiro de Geografia e Estatística (IBGE), para o ano de 2017, o Brasil tinha aproximadamente 209 milhões de habitantes, sendo que deste percentual, 51\% eram compostos por mulheres.

Entretanto, mesmo representando mais da metade da população total do país, os resultados eleitorais relativos as quatro últimas eleições (2012, 2014, 2016 e 2018), mostram que as mulheres representavam em média apenas 13\% do total de eleitos para os cargos legislativos, seja na esfera federal, estadual ou municipal.

É no contexto dessa discussão que este artigo se insere. Nele, procurou-se estudar a representação feminina na política municipal, tendo como elemento de investigação as eleições de 2012 e 2016 para a formação das bancadas nas Câmaras Municipais.

Não obstante a constatação da sub-representação feminina na esfera dos cargos representativos, o estudo procurou avaliar se há diferenças na eleição de mulheres na esfera do poder local em relação a duas variáveis indicadas na literatura: uma de natureza institucional, no caso, a magnitude dos distritos, e outra de natureza política, a ideologia partidária.

Para a construção de hipóteses, o artigo buscou referência nos estudos sobre a relação entre a eleição de candidatos e as diferenças existentes entre estados e regiões do país (NICOLAU, 1996; AMES, 1986) que indicam que devido à existência de uma elevada fragmentação partidária, a atuação dos partidos e a competição eleitoral se apresente de forma diferenciada entre os estados e regiões do país. Desta forma, acredita-se que o sistema federativo brasileiro faz com que o recrutamento de candidaturas femininas e, consequentemente, a eleição de mulheres, siga padrões também diferentes entre os estados e municípios componentes da federação.

No Brasil, em razão da composição federativa dos poderes legislativos e executivos, os distritos eleitorais relacionam-se com a dimensão 
geográfica que diferenciam os espaços de competição política. Na esfera estadual e federal os distritos são constituídos pelos 26 estados que compõem a federação brasileira, e na esfera da composição do poder local os distritos eleitorais referem-se aos 5.570 municípios que estão distribuídos entre os 26 estados brasileiros.

Entretanto, como o processo de representação política está diretamente relacionado com a base demográfica presente em cada território, e como os diversos territórios têm dimensões populacionais diferenciadas, a formação das bancadas e o número de eleitos por cada distrito segue esta diferenciação populacional. É justamente o número de vagas disponíveis em cada território eleitoral que é chamada de magnitude dos distritos.

A Constituição Federal em seu artigo 29 estabelece o número de cadeiras que deverão compor as Câmaras Municipais de acordo com o tamanho da população. A variação entre os distritos varia de nove a 55 vagas distribuídas em diversas faixas populacionais. Os municípios com menores populações elegem nove vereadores e, de acordo com o tamanho da população, esta faixa subirá até o limite máximo de 55 vereadores.

Meireles e Andrade (2017), em um estudo sobre a eleição de candidatos na esfera do poder local, já indicavam a relação positiva entre a eleição de mulheres e a magnitude eleitoral, indicando que o aumento de uma cadeira na magnitude eleitoral aumenta em cerca de 20 pontos percentuais as chances da eleição de um candidato do sexo feminino.

Isto se estabelece pelo fato de que quanto maior a magnitude, maiores os incentivos para o recrutamento de candidaturas mais diversificadas, o que abriria espaço para que minorias tenham mais oportunidades de acesso a cargos eletivos, sem que, com isso, outros grupos percam espaço de representação.

Por outro lado, nas situações em que existem poucas vagas em disputa, há certa tendência de os líderes partidários vetarem as candidaturas de determinados grupos para promover candidaturas de seus líderes. Desse modo, quanto maior o número de candidatos disputando uma cadeira, aliado a um menor coeficiente eleitoral e uma maior quantidade de vagas no território, acredita-se que reduziriam as desvantagens produzidas pela esfera institucional e aumentariam as chances das mulheres conseguirem se eleger (MEIRELES; ANDRADE, 2017). 
Por esta razão, a magnitude dos distritos pareceu-nos uma variável interessante para avaliar a existência (ou não) de constrangimentos institucionais para a eleição de mulheres e diferenciação entre os gêneros e partiu-se da hipótese que quanto mais elevada a magnitude dos distritos, mais favoráveis as condições para a eleição de mulheres para os parlamentos municipais.

Em relação à questão ideológica, há na literatura alguns indicadores que identificam a participação de minorias com uma agenda mais vinculada aos partidos de esquerda. Isto se estabeleceria pelo fato de que os partidos de esquerda, devido à sua vinculação com movimentos populares, possibilitariam maior abertura para a participação de representantes de grupos minoritários no interior das organizações partidárias, e como consequência, maior abertura para a participação política deste segmento nas listas de candidaturas (BOHN, 2010).

Peixoto, Goulart e Silva (2017) compartilham da mesma posição ao identificar a ideologia partidária como um componente importante para verificar a incorporação de minorias no processo político. Para o autor, os partidos de esquerda foram os primeiros a adotar cotas para inserção de mulheres na vida política, sendo que esta decisão exerceu o que o autor chama de "efeito contágio", que levou os partidos de centro e de direita a estabelecerem políticas de incentivo para o ingresso das mulheres no jogo eleitoral, após a percepção que a inclusão feminina melhorava seu desempenho nos municípios e, consequentemente, melhorava os resultados eleitorais.

Para Sacchet (apud PAIVA, 2012), a ideologia partidária se estabelece como peça fundamental para o entendimento do jogo político e para o recrutamento das candidaturas. Para a autora, quanto mais próximo ao espectro político de esquerda, mais inclinado a selecionar mulheres para os seus quadros partidários, por defenderem princípios igualitários e, por isso, mais suscetíveis em aceitar as demandas em favor das igualdades de gênero (SACCHET apud PAIVA, 2012).

Por esta razão, a dimensão ideológica assume grande relevância nos estudos que procuram entender os mecanismos de inclusão ou exclusão das mulheres na esfera da representação política.

Nossa pesquisa partiu da hipótese que os partidos vinculados ao campo ideológico das esquerdas, devido à sua vinculação com os movimentos sociais de defesa das minorias, apresentam melhores condições para o recrutamento e eleição de mulheres para os cargos eletivos do poder local. 


\section{A influência da magnitude dos distritos na eleição de mulheres}

Para avaliar a representação de mulheres nas eleições de 2012 e 2016, a pesquisa se utilizou do banco de dados do TSE relativo à distribuição de candidaturas nestas eleições, identificando as seguintes variáveis: magnitude dos distritos, proporção de mulheres eleitas distribuídas por município, cargo em disputa, partido de origem e seu respectivo posicionamento ideológico.

Para relacionar a eleição de mulheres com a magnitude dos distritos utilizou-se do modelo de correlação de Spearman que tem como objetivo verificar a existência de padrões de relacionamento entre duas variáveis quantitativas de natureza distinta. Este modelo pareceu adequado aos objetivos da pesquisa, pois permite perceber tanto a existência de correlação quanto à sua intensidade.

Para facilitar a análise dos dados e permitir a comparação entre as unidades da federação, agregamos os resultados das correlações municipais por estado para verificar a existência de diferenças e semelhanças entre eles. É preciso levar em consideração que o número de municípios por estado e o quadro individual da magnitude por cada município pode ter influenciado na determinação dos resultados, entretanto, como o objetivo da pesquisa foi apenas determinar a presença de padrões de relacionamento entre a magnitude e a eleição de mulheres, acreditamos que a metodologia empreendida pode sim apresentar-se como um sinalizador da presença de associação entre a magnitude e a eleição de mulheres na esfera do poder local.

O modelo de correlação de Spearman parte da suposição que duas variáveis de grandezas distintas podem se relacionar no mesmo fenômeno. Entretanto, esta relação pode se estabelecer de forma positiva ou negativa. A correlação é positiva quando valores crescentes da variável independente (magnitude dos distritos) impacta de forma também crescente na variável dependente (mulheres eleitas por município). A correlação passa a ser negativa quando valores crescentes da magnitude dos distritos impacta de forma decrescente no número de mulheres eleitas por município.

Os resultados da correlação podem indicam também se a correlação entre as duas variáveis se apresentou qualitativamente de forma forte, moderada ou fraca, seja na perspectiva negativa ou positiva. Os resultados 
do modelo de correlação de Spearman podem ser interpretados a partir das seguintes situações descritas no quadro abaixo.

Quadro 1 - Interpretação da correlação

\begin{tabular}{|c|c|}
\hline Valor & Força \\
\hline 1 & Correlação perfeita positiva \\
\hline 0,909 a 0,700 & Correlação forte positiva \\
\hline 0,701 a 0,400 & Correlação moderada positiva \\
\hline 0,401 a 0,100 & Correlação fraca positiva \\
\hline 0 & Sem correlação \\
\hline$-0,100$ a $-0,400$ & Correlação fraca negativa \\
\hline$-0,401$ a $-0,701$ & Correlação moderada negativa \\
\hline$-0,700$ a $-0,909$ & Correlação forte negativa \\
\hline-1 & Correlação perfeita negativa \\
\hline
\end{tabular}

Os resultados apresentados, derivadas da análise para os anos de 2012 e 2016 indicam a existência de uma associação positiva entre magnitude dos distritos e a eleição de mulheres, entretanto, na desagregação dos dados por estados nas duas eleições, o modelo demonstrou que esta associação não se manteve continua tanto no tempo quanto no espaço, sendo mais forte em dada eleição e menor em outra e também com certa diferença entre as unidades da federação.

Tabela 1 - Relação entre magnitude dos distritos e eleição de mulheres para as Câmaras Municipais - Correlação de Spearman 2012 e 2016

\begin{tabular}{|c|c|c|c|c|}
\hline ESTADO & $\mathbf{2 0 1 2}$ & CORRELAÇÃO & $\mathbf{2 0 1 6}$ & CORRELAÇÃO \\
\hline $\mathbf{A C}$ & 0,144 & $\begin{array}{c}\text { Correlação fraca } \\
\text { positiva }\end{array}$ & 0,326 & Correlação fraca positiva \\
\hline $\mathbf{A L}$ & $-0,053$ & $\begin{array}{c}\text { Correlação fraca } \\
\text { negativa }\end{array}$ & 0,074 & Correlação fraca positiva \\
\hline $\mathbf{A M}$ & 0,110 & $\begin{array}{c}\text { Correlação fraca } \\
\text { positiva }\end{array}$ & 0,177 & Correlação fraca positiva \\
\hline $\mathbf{A P}$ & 0,303 & $\begin{array}{c}\text { Correlação fraca } \\
\text { positiva }\end{array}$ & 0,105 & Correlação fraca positiva \\
\hline $\mathbf{B A}$ & 0,134 & $\begin{array}{c}\text { Correlação fraca } \\
\text { positiva }\end{array}$ & 0,090 & Correlação fraca positiva \\
\hline $\mathbf{C E}$ & $-0,012$ & $\begin{array}{c}\text { Correlação fraca } \\
\text { negativa }\end{array}$ & 0,058 & Correlação fraca positiva \\
\hline
\end{tabular}




\begin{tabular}{|c|c|c|c|c|}
\hline ES & 0,015 & $\begin{array}{c}\text { Correlação fraca } \\
\text { positiva }\end{array}$ & 0,163 & Correlação fraca positiva \\
\hline GO & 0,108 & $\begin{array}{c}\text { Correlação fraca } \\
\text { positiva }\end{array}$ & 0,136 & Correlação fraca positiva \\
\hline MA & 0,131 & $\begin{array}{c}\text { Correlação fraca } \\
\text { positiva }\end{array}$ & 0,106 & Correlação fraca positiva \\
\hline MG & 0,073 & $\begin{array}{c}\text { Correlação fraca } \\
\text { positiva }\end{array}$ & 0,070 & Correlação fraca positiva \\
\hline MS & 0,087 & $\begin{array}{c}\text { Correlação fraca } \\
\text { positiva }\end{array}$ & 0,090 & Correlação fraca positiva \\
\hline MT & 0,044 & $\begin{array}{c}\text { Correlação fraca } \\
\text { positiva }\end{array}$ & 0,050 & Correlação fraca positiva \\
\hline PA & 0,249 & $\begin{array}{c}\text { Correlação fraca } \\
\text { positiva }\end{array}$ & 0,179 & Correlação fraca positiva \\
\hline PB & 0,164 & $\begin{array}{c}\text { Correlação fraca } \\
\text { positiva }\end{array}$ & $-0,057$ & Correlação fraca negativa \\
\hline PE & 0,042 & $\begin{array}{c}\text { Correlação fraca } \\
\text { positiva }\end{array}$ & 0,184 & Correlação fraca positiva \\
\hline PI & 0,116 & $\begin{array}{c}\text { Correlação fraca } \\
\text { positiva }\end{array}$ & 0,072 & Correlação fraca positiva \\
\hline PR & 0,067 & $\begin{array}{c}\text { Correlação fraca } \\
\text { positiva }\end{array}$ & 0,171 & Correlação fraca positiva \\
\hline RJ & 0,168 & $\begin{array}{c}\text { Correlação fraca } \\
\text { positiva }\end{array}$ & 0,120 & Correlação fraca positiva \\
\hline $\mathbf{R N}$ & 0,093 & $\begin{array}{c}\text { Correlação fraca } \\
\text { positiva }\end{array}$ & 0,171 & Correlação fraca positiva \\
\hline RO & 0,064 & $\begin{array}{c}\text { Correlação fraca } \\
\text { positiva }\end{array}$ & 0,044 & Correlação fraca positiva \\
\hline $\mathbf{R R}$ & $-0,052$ & $\begin{array}{c}\text { Correlação fraca } \\
\text { negativa }\end{array}$ & 0,154 & Correlação fraca positiva \\
\hline RS & 0,122 & $\begin{array}{c}\text { Correlação fraca } \\
\text { positiva }\end{array}$ & 0,055 & Correlação fraca positiva \\
\hline SC & $-0,054$ & $\begin{array}{c}\text { Correlação fraca } \\
\text { negativa }\end{array}$ & $-0,030$ & Correlação fraca negativa \\
\hline SE & 0,167 & $\begin{array}{c}\text { Correlação fraca } \\
\text { positiva }\end{array}$ & 0,277 & Correlação fraca positiva \\
\hline $\mathrm{SP}$ & 0,046 & $\begin{array}{c}\text { Correlação fraca } \\
\text { positiva }\end{array}$ & 0,063 & Correlação fraca positiva \\
\hline TO & 0,020 & $\begin{array}{c}\text { Correlação fraca } \\
\text { positiva }\end{array}$ & $-0,118$ & Correlação fraca negativa \\
\hline
\end{tabular}

Fonte: TSE (2020) e IBGE (2010). 
Para a eleição de 2012, os dados indicaram uma associação positiva em 22 estados componentes da geografia política do país, evidenciando a capacidade explicativa da magnitude dos distritos para entender a eleição de mulheres na esfera das eleições legislativas municipais. Entretanto, devido à grande quantidade de municípios e a diversidade de filtros que a eleição de mulheres enfrenta na esfera da representação local, esta variável se enquadrou em todos os casos positivos numa condição de fragilidade, o que indica que, mesmo apresentando certa relação, a associação entre magnitude dos distritos e eleição de mulheres não apresenta capacidade explicativa suficiente para entender a eleição de mulheres no Brasil, precisando incorporar outras variáveis para a melhor compreensão deste fenômeno.

É válido lembrar que em apenas quatro estados a situação foi estabelecida de forma inversa, ou seja, a magnitude reduziu a eleição de mulheres, entretanto, como nestas situações a correlação também se enquadrou na condição de negativa fraca, isto reforça a suposição de que a magnitude apresenta pouca relação com o fenômeno investigado.

Para a eleição de 2018 esta situação pouco se alterou. Em 23 estados a relação entre magnitude e eleição de mulheres se estabeleceu na condição de positividade, entretanto, a intensidade desta relação continuou como sendo fraca, o que manteve o entendimento de que a magnitude não se traduz como uma variável suficientemente forte para explicar a eleição de mulheres na esfera dos municípios, contrariando, portanto, parte da literatura sobre o tema.

Nas situações em que os dados indicaram uma relação negativa entre magnitude e eleição de mulheres (três estados) a intensidade também se estabeleceu de forma fraca, o que reforça a conclusão sobre a incapacidade da magnitude em responder pelo aumento ou diminuição da eleição de mulheres entre os municípios componentes dos estados brasileiros.

\subsection{Relação entre a eleição de mulheres e a ideologia partidária}

Já no caso da associação entre a eleição de mulheres e a ideologia partidária, utilizou-se o método descritivo, a partir da proporção de candidaturas eleitas e não eleitas pelos partidos, devidamente agregados por ideologia, segundo a abordagem da literatura sobre o tema.

A literatura que mobiliza a ideologia partidária como elemento de análise das condições de elegibilidade de determinados grupos reconhece que o conceito de ideologia é complexo e tem diversos alcances e significa- 
dos, de acordo com diversas variáveis que vão desde o contexto histórico, social, cultural, político e o lugar onde ele pode ser inserido.

De acordo com Bobbio (2011), a ideologia partidária se refere ao conjunto de ideias, pensamentos, doutrinas ou visões de mundo de um indivíduo ou de determinado grupo, orientado para suas ações sociais e políticas.

A análise dos dados eleitorais de 2012 e 2016 possibilita entender se existem diferenças eleitorais significativas ne eleição entre homens e mulheres, de acordo com a ideologia partidária.

Para nossa hipótese, definimos, a partir de referenciais teóricos, o quadro de partidos, entre esquerda, direita, centro-direita e centro-esquerda. Optamos por uma subdivisão do centro, para melhor estudar a nossa hipótese.

Dois conceitos podem ser trazidos à luz para definição de partidos de direita e de esquerda. O primeiro é referente ao papel do Estado, que para os partidos de direita deve ser mínimo, garantindo somente a ordem pública enquanto que para os partidos de esquerda o Estado deve ser ativo na redução das desigualdades (PEREIRA, 1997).

Quando se fala em Estado mínimo, estamos associando a uma menor intervenção dos governos na economia, na manutenção de uma máquina estatal ou em projetos e leis que garantam a participação de movimento sub-representados.

É válido observar que os conceitos de direita e esquerda não são conceitos absolutos, que podem variar de acordo com o tempo, o lugar e a situação política de cada sociedade (BOBBIO, 2011), mas os elementos fundamentais nos permitem fazer uma inferência que nos liga a conceitos de inclusão e de interesses coletivos ligados a um maior intervencionismo institucional, característico dos grupos de esquerda, enquanto que a decisão individual, vinculada ao livre mercado, sem muita ação das instituições, é ligada a grupos de direita.

Para a determinação da situação política do país na eleição de 2012 e 2016, frente à definição ideológica dos partidos, utilizou-se uma classificação conceitual já estabelecida pela literatura de acordo com a descrição no quadro a seguir: 
Quadro 2 - Classificação dos partidos por ideologia

\begin{tabular}{|l|l|}
\hline IDEOLOGIA & PARTIDOS \\
\hline DIREITA & $\begin{array}{l}\text { PSL, PRP, PL/PR, PRB, PTB, PP, DEM, SD/ } \\
\text { SOLIDARIEDADE, PSD, PHS, PODEMOS/PODE, } \\
\text { PSC, PTC, PRTB, PSDC, DC, PTN, PATRIOTAS, NOVO }\end{array}$ \\
\hline CENTRO-DIREITA & PEN, PSDB, PPS, PV, PMDB, MDB \\
\hline CENTRO-ESQUERDA & PDT, PMN, PT do B, AVANTE, PMB, PROS \\
\hline ESQUERDA & PC do B, PT, PSB, PSOL, REDE, PPL, PSTU, PCB e PCO \\
\hline
\end{tabular}

Fonte: Elaboração própria com base na classificação da pesquisa de Carreirão (2006), Braga e Pimentel Júnior (2013) e Bobbio (2011).

A maior proporção dos partidos estão situados no campo ideológico da direita e centro-direita, o que permite um maior número de candidatos, principalmente nas eleições proporcionais. Isso impacta no resultado, pois aumenta a competição interna entre as mulheres quando agregamos os dados ligados a este campo ideológico.

\subsubsection{A ideologia partidária e a eleição de mulheres em 2012}

Nas eleições para os cargos proporcionais no ano de 2012, verificou-se que 28 partidos disputaram as vagas para o cargo de vereadores(as) nos diversos municípios do país, uma verdadeira legião de agremiações partidárias, que conseguiram representação nas Câmaras Municipais.

A utilização da proporcionalidade nas eleições visa duas preocupações: a heterogeneidade de representação, buscando espelhar a diversidade da sociedade nos parlamentos e a correspondência dos votos recebidos por um partido e diversidade de gênero na ocupação de cadeiras.

Tabela 2 - Vereadores por ideologia e gênero em 2012

\begin{tabular}{|l|c|c|c|c|c|c|}
\hline Gênero & \multicolumn{2}{|c|}{ Feminino } & \multicolumn{2}{c|}{ Masculino } & \multicolumn{2}{c|}{ Total } \\
\hline Partidos & Freq. & $\mathbf{0}$ & Freq. & $\mathbf{\%}$ & Freq. & \% \\
\hline PMDB & 1128 & 14,15 & 6841 & 85,85 & 7969 & 13,88 \\
\hline PSDB & 723 & 13,75 & 4537 & 86,25 & 5260 & 9,16 \\
\hline PT & 738 & 14,23 & 4447 & 85,77 & 5185 & 9,03 \\
\hline PP & 677 & 13,71 & 4261 & 86,29 & 4938 & 8,60 \\
\hline PSD & 650 & 13,93 & 4016 & 86,07 & 4666 & 8,12 \\
\hline PDT & 456 & 12,45 & 3207 & 87,55 & 3663 & 6,38 \\
\hline PTB & 488 & 13,63 & 3093 & 86,37 & 3581 & 6,23 \\
\hline
\end{tabular}




\begin{tabular}{|l|c|c|c|c|c|c|}
\hline PSB & 431 & 12,12 & 3124 & 87,88 & 3555 & 6,19 \\
\hline DEM & 435 & 13,24 & 2850 & 86,76 & 3285 & 5,72 \\
\hline PR & 402 & 12,60 & 2789 & 87,40 & 3191 & 5,56 \\
\hline PPS & 230 & 12,34 & 1634 & 87,66 & 1864 & 3,25 \\
\hline OUTROS & 1298 & 12,63 & 8.979 & 87,37 & 10277 & 17,89 \\
\hline TOTAL & $\mathbf{7 6 5 6}$ & $\mathbf{1 3 , 3 3}$ & $\mathbf{4 9 7 7 8}$ & $\mathbf{8 6 , 6 7}$ & $\mathbf{5 7 4 3 4}$ & $\mathbf{1 0 0 , 0 0}$ \\
\hline
\end{tabular}

Fonte: Tribunal Superior Eleitoral - TSE (2020).

NOTA: Na categoria OUTROS incluímos todos os partidos que elegeram menos de 3\% dos vereadores na eleição de 2012. São eles: PC do B (1,70\%), PCB (0,01\%), PHS (0,95\%), PMN (1,06\%), PPL (0,31\%), PPS (3,25\%), PRB (2,10\%), PRP (1,01\%), PRTB $(0,73 \%)$, PSC $(2,56 \%)$, PSDC (2,78\%), PSL (1,32\%), PSOL (0,09\%), PSTU $(0,001 \%)$, PT do B $(0,93 \%)$, PTC $(0,84 \%)$, PTN $(0,75 \%)$ e PV $(2,76 \%)$.

Numa perspectiva individual por partido político no Brasil, os dados indicam que na eleição de 2012 não houve diferenças significativas entre os partidos políticos quanto à capacidade de incluir as mulheres na esfera da representação política.

$\mathrm{Na}$ relação entre homens e mulheres eleitas por partido, as agremiações com melhores resultados proporcionais na inclusão de mulheres eleitas foram PMDB, PT, PSD, PSDB, PP, PTB e DEM, mas, percebe-se a existência de pouca variação entre eles, situando entre 12 e 14\% do total de mulheres eleitas pelos partidos no ano de 2012.

$\mathrm{Na}$ agregação dos partidos por campo ideológico os dados não estabeleceram grandes alterações, indicando que a ideologia partidária não se apresenta como um indicador relevante para diferenciar a eleição de mulheres na esfera da representação política no Brasil.

Tabela 3 - Percentual de vereadores por ideologia e gênero em 2012

\begin{tabular}{|l|l|l|l|l|}
\hline Gênero & \multicolumn{2}{|c|}{ Feminino } & \multicolumn{2}{c|}{ Masculino } \\
\hline Ideologia & \multicolumn{1}{|c|}{ Freq. } & \multicolumn{1}{c|}{ Freq. } & \multicolumn{1}{c|}{$\%$} \\
\hline Direita & 3436 & 13,21 & 22567 & 86,79 \\
\hline Centro-Direita & 2256 & 13,53 & 14420 & 86,47 \\
\hline Centro-Esquerda & 632 & 13,15 & 4174 & 86,85 \\
\hline Esquerda & 1332 & 13,39 & 8617 & 86,61 \\
\hline
\end{tabular}

Fonte: Tribunal Superior Eleitoral - TSE (2020). 


\subsubsection{A ideologia partidária e a eleição de mulheres em 2016}

Na eleição de 2016, foram 33 partidos representados, mas do ponto de vista do recrutamento e eleição de mulheres por partidos isolados, verificou-se que não há grandes alterações no quadro geral de sub-representação feminina na esfera da representação política nas Câmaras Municipais.

É válido destacar o caso do PT, que na eleição de 2012 foi o terceiro maior partido na eleição de vereadores, mas na eleição de 2016 passou para a décima posição, perdendo diversas cadeiras no cômputo geral da formação das bancadas nas Câmaras Municipais.

Por outro, na relação entre os gêneros derivados das candidaturas por partido, o PT foi o que mais elegeu proporcionalmente mulheres entre os seus eleitos, com 15,74\% de eleição de candidaturas femininas. Logo a seguir vieram PMDB, PDT, PP e PSD que ficaram em torno de 14\% de candidatas femininas entre os eleitos destes partidos.

Tabela 4 - Vereadores por partidos e gênero em 2016

\begin{tabular}{|l|c|c|c|c|c|c|}
\hline \multirow{2}{*}{ Partido } & \multicolumn{2}{|c|}{ Feminino } & \multicolumn{2}{c|}{ Masculino } & \multicolumn{2}{c|}{ Total } \\
\cline { 2 - 7 } & Qtd & $\mathbf{0}$ & Qtd & \% & Qtd & $\%$ \\
\hline PMDB & 1101 & 14,56 & 6463 & 85,44 & 7564 & 13,05 \\
\hline PSDB & 710 & 13,23 & 4655 & 86,77 & 5365 & 9,26 \\
\hline PP & 669 & 14,11 & 4073 & 85,89 & 4742 & 8,18 \\
\hline PSD & 651 & 14,02 & 3994 & 85,98 & 4645 & 8,02 \\
\hline PDT & 552 & 14,52 & 3249 & 85,48 & 3801 & 6,56 \\
\hline PSB & 471 & 12,96 & 3162 & 87,04 & 3633 & 6,27 \\
\hline PTB & 428 & 13,96 & 2637 & 86,04 & 3065 & 5,29 \\
\hline PR & 354 & 11,73 & 2663 & 88,27 & 3017 & 5,21 \\
\hline DEM & 378 & 13,02 & 2525 & 86,98 & 2903 & 5,01 \\
\hline PT & 443 & 15,74 & 2371 & 84,26 & 2814 & 4,86 \\
\hline Outros & 2089 & 12,74 & 14307 & 87,26 & 16396 & 28,29 \\
\hline Total & 7846 & 13,54 & 50099 & 86,46 & 57945 & 100,00 \\
\hline
\end{tabular}

Fonte: Tribunal Superior Eleitoral - TSE (2020).

NOTA: Na categoria OUTROS incluímos todos os partidos que elegeram menos de 3\% dos vereadores na eleição de 2016. São eles: PPS (2,89\%), PRB (2,80\%), PSC (2,64\%), PV $(2,63 \%)$, SD $(2,48 \%)$, PC do B $(1,74 \%)$, PROS $(1,70 \%)$, PSL $(1,52 \%)$, PHS $(1,51 \%)$, PTN $(1,32 \%)$, PRP $(1,06 \%)$, PTC $(0,99 \%)$, PMN $(0,91 \%)$, PEN $(0,90 \%)$, PT do B $(0,84 \%)$, PSDC $(0,72 \%)$, PRTB $(0,67 \%)$, PMB $(0,37 \%)$, REDE $(0,31 \%)$, PPL $(0,19 \%)$, PSOL $(0,10 \%)$, NOVO $(0,01 \%)$, PCB $(0,01 \%)$. 
Em uma perspectiva comparativa, a eleição de 2016 teve um aumento, mesmo que pequeno, na eleição proporcional de mulheres entre os gêneros quando levado em consideração o desempenho partidário, saindo de 13,33\% de mulheres eleitas em 2012 para 13,54\% em 2016. Esse aumento, entretanto, foi estatisticamente pouco significativo e sem capacidade de alterar a condição de sub-representação feminina na política local.

Tabela 5 - Percentual de vereadores por ideologia e gênero em 2016

\begin{tabular}{|l|c|c|c|c|}
\hline \multirow{2}{*}{ Ideologia } & \multicolumn{2}{|c|}{ Feminino } & \multicolumn{2}{c|}{ Masculino } \\
\cline { 2 - 5 } & Freq. & $\mathbf{\%}$ & Freq. & \% \\
\hline Direita & 3682 & 13,40 & 23795 & 86,60 \\
\hline Centro-Direita & 2239 & 13,45 & 14412 & 86,55 \\
\hline Centro-Esquerda & 836 & 13,90 & 5179 & 86,10 \\
\hline Esquerda & 1089 & 13,96 & 6713 & 86,04 \\
\hline
\end{tabular}

Fonte: Tribunal Superior Eleitoral - TSE (2020).

$\mathrm{Na}$ agregação por ideologia partidária, os dados da eleição de 2016 indicam o melhor desempenho dos partidos de esquerda e centro-esquerda na incorporação de mulheres em seus quadros de vereadores eleitos, com $13,96 \%$ e $13,90 \%$, respectivamente, contra $13,40 \%$ e $13,45 \%$ do bloco ideológico de centro-direita e direita.

Entretanto, como os valores percentuais entre os blocos ideológicos estão muito próximos, isto indica que, de forma geral, não há indicativos que a ideologia partidária represente uma variável explicativa capaz de alterar a condição de sub-representação feminina no quadro da política eleitoral, pois, pelos resultados apresentados esta situação acontece em todos os partidos, independentemente da ideologia.

\section{Conclusões}

A sub-representação feminina na política eleitoral se constitui como um fenômeno que chama a atenção de pesquisadores do mundo inteiro pela evidência de que a manutenção desta situação gera um problema na qualidade da representação estabelecida pelos regimes democráticos.

Apesar dos avanços que o tema tem conseguido nas últimas décadas nas agendas de pesquisa da área de Ciência Política, ainda há muito a se revelar sobre os fatores que condicionam a situação de sub-representação 
feminina na política brasileira, principalmente na política local, que se estabelece em uma arena política pouco estudada.

Neste artigo, procurou-se evidenciar se duas variáveis indicadas na literatura - a magnitude dos distritos e a ideologia partidária - apresentam alguma capacidade explicativa para mensurar o fenômeno da sub-representação feminina na política local.

A partir de uma análise comparativa da eleição de 2012 e 2016 para as Câmaras Municipais em todos os municípios brasileiros e, utilizando-se de um modelo de correlação, a pesquisa procurou verificar a existência (ou não) de correlação entre as diferentes configurações dos sistemas de representação municipal e a eleição de mulheres.

Além disso, a pesquisa procurou avaliar a possiblidade da influência da ideologia partidária como uma variável capaz de responder pelos casos de sucesso na eleição de mulheres. Para isso, partiu-se da hipótese que a aproximação dos partidos de esquerda com os movimentos de inclusão social de minorias, produziria um efeito positivo para o recrutamento de mulheres para as arenas decisórias, e, portanto, trariam maiores probabilidades para o sucesso eleitoral deste grupo social.

A metodologia empreendida e os resultados apresentados, entretanto, não indicaram que estas duas variáveis apresentam capacidade explicativa suficiente para entender a eleição de mulheres na arena das eleições legislativas municipais.

No caso da magnitude, a comparação entre os diversos municípios componentes da federação brasileira, agregados por estados, não indicou uma associação suficientemente forte para caracterizar a magnitude como responsável pelo maior sucesso das mulheres nas Câmaras Municipais.

Da mesma forma, a comparação do sucesso eleitoral de mulheres com a ideologia partidária não demonstrou diferenças marcantes entre os partidos, que possam mensurar o peso desta variável na eleição de mulheres no Brasil.

Desta forma, acreditamos que outras estudos que possam testar novas variáveis e novas metodologias se tornem necessárias para desvendar os fatores que produzem o fenômeno da sub-representação feminina que compromete significativamente a qualidade e a inclusão social, tão caros para os regimes democráticos na atualidade. 


\section{Referências}

AMES, B. O Congresso e a política orçamentária no Brasil durante o período pluripartidário. Dados - Revista de Ciências Sociais, Rio de Janeiro, v. 29, n. 2, 1986.

AVELAR, L.; LIMA, F. D. Lentas mudanças: o voto e a política tradicional. Lua Nova, n. 49, p. 195-223, 2000.

AVELAR, L. Mulheres na elite política brasileira. São Paulo: Fundação Konrad Adenauer; Editora da Unesp, 2001.

AYRES, M. Elementos de bioestatística: a seiva do açaizeiro. 2. ed. Tefé, AM: Instituto Mamirauá, 2012.

BIROLI, F.; MIGUEL, L. F. Feminismo e política: uma introdução. São Paulo: Boitempo, 2014.

BOBBIO, N. Direita e esquerda: razões e significados de uma distinção política. São Paulo: Editora da Unesp, 2011.

BOHN, S. R. Mulher para presidente? gênero e política da perspectiva dos eleitores brasileiros. Opinião Pública, Campinas, v. 14, n. 2, p. 352-379, 2008.

BOHN, S. R. Mulheres brasileiras na disputa do legislativo municipal. Perspectivas: Revista de Ciências Sociais, v. 35, 2010.

BRASIL. IBGE. Censo Demográfico, 2010. Disponível em: www.ibge.gov. br. Acesso em: 12 dez. 2018.

BUSSAB, W. O.; MORETTIN, P. A. Estatística básica. São Paulo: Saraiva, 2010.

BRAGA, M. S. S.; PIMENTEL JÚNIOR, J. Estrutura e organização partidária municipal nas eleições de 2012. Cadernos ADENAUER, v. 2, p. 13-36, 2013.

CARREIRÃO, Y. S. Ideologia e partidos políticos: um estudo sobre coligações em Santa Catarina. Opinião Pública, Campinas, v. 12, n. 1, abr./maio 2006.

CALLEGARI-JACQUES, S. M. Bioestatística: princípios e aplicações. Porto Alegre: Artmed, 2009. 
MEIRELES, F.; ANDRADE, L. V. R. Magnitude eleitoral e representação de mulheres nos municípios brasileiros. Revista de Sociologia e Política, Curitiba, v. 25, n. 63, p. 79-101, set. 2017. Disponível em: https://revistas.ufpr.br/ rsp/issue/view/2422. Acesso em: 7 nov. 2018.

MOISÉS, J. Á.; SANCHEZ, B. R. Representação política das mulheres e qualidade da democracia: o caso do Brasil. In: MOISÉS, J. Á. (org.). O Congresso Nacional, os partidos políticos e o sistema de integridade: representação, participação e controle institucional no Brasil contemporâneo. Rio de Janeiro: Konrad Adenauer Stiftung, 2014. p. 89-115.

NICOLAU, J. M. Multipartidarismo e democracia: um estudo sobre o sistema partidário brasileiro (1985-1994). Rio de Janeiro: Fundação Getulio Vargas, 1996.

NICOLAU, J. M. O efeito dos sistemas eleitorais sobre o sistema partidário no Brasil. Minas Gerais. In: XVIII ENCONTRO ANUAL DA ANPOCS, Caxambu, 1994. Anais... Disponível no link: https:/ /www.anpocs.com/ index.php/encontros/papers/18-encontro-anual-da-anpocs/gt-17/gt06-4/ 7427-jaironicolau-partidos/file. Acesso em: 26 dez. 2019.

NICOLAU, J. M. Sistemas eleitorais. 5. ed., v. 1. Rio de Janeiro: FGV, 2004.

PEREIRA, L. C. B. Por um partido democrático de esquerda e contemporâneo. Lua Nova: Revista de Cultura e Política, n. 39, p. 53-71, 1997.

PONCELA, A. M. F. Hombres, mujeres y política: una mirada desde la opinión pública y sus protagonistas. México: UNAM, 1997.

PEIXOTO, V.; GOULART, N.; SILVA, G. Os partidos políticos e as mulheres: a sub-representação eleitoral feminina nas eleições proporcionais de 2012. Almanaque de Ciência Política, Vitória, v. 1, n. 1, p. 15-29, jan. 2017. Disponível em: http://www.periodicos.ufes.br/almanaque/article/ view/16038. Acesso em: 8 nov. 2018.

PAIVA, D. Mulheres, política e poder. v. 1. Goiânia: Cânone, 2011. ISBN 978-85-8058-002-0.

RODRIGUES, A. Eleições de 2006 no Brasil: a difícil conquista de mandatos eletivos por mulheres. Brasília: CFEMEA, nov. 2006. Disponível em: http:/ / www.cfemea.org.br/temasedados/detalhes.asp?IDTemasDados=166. Acesso em: 12 mar. 2019. 
RIBEIRO, E. A. Cultura política e gênero no Brasil: estudo exploratório sobre as bases da sub-representação feminina. In: BAQUERO, M. (org.). Cultura(s) política(s) e democracia no século XXI na América Latina. Porto Alegre: Ed. da UFRGS, 2011.

SENADO FEDERAL (org.). Mulheres na Política. v. 1. Brasília: Senado Federal, 2014.

SPOHR, A. P.; MAGLIA, C.; MACHADO, G.; OLIVEIRA, J. O. Participação política de mulheres na América Latina: o impacto de cotas e de lista fechada. Rev. Estud. Fem. [online], v. 24, n. 2, p. 417-441, 2016. ISSN 0104026X. DOI: http://dx.doi.org/10.1590/1805-9584-2016v24n2p417.

SACCHET, T. Partidos políticos e (sub) representação feminina: um estudo sobre recrutamento legislativo e financiamento de campanhas. In: PAIVA, D. (org.). Mulheres, poder e política. Goiânia: Cânone, 2012. p. 159-186.

TAVARES, J. A. G. Sistemas eleitorais nas democracias contemporâneas: teoria, instituições, estratégia. Rio de Janeiro: Relume-Dumará, 1994

Alan da Silva Pereira - Mestre em Ciência Política pela UFPA - Programa de Pós-Graduação em Ciência Política - PPGCP. E-mail: alanpereiramkt@gmail.com. ORCID - https://orcid.org/0000-0002-8268-2409.

Carlos Augusto da Silva Souza - Mestre e Doutor em Ciência Política pelo Instituto Universitário de Pesquisas do Rio de Janeiro (IUPERJ), professor/pesquisador da Universidade Federal do Pará onde atua no curso de Ciências Sociais e no Programa de Mestrado em Ciência Política. E-mail: carlossouza@ufpa.br. ORCID - https://orcid.org/00000003-0251-6089.

Cloves Luiz Pereira Oliveira - Doutorado em Ciência Política pelo Instituto Universitário de Pesquisa do Rio de Janeiro (2007). Departamento de Ciência Política - Universidade Federal da Bahia. E-mail: cloves.luiz@uol.com.br. ORCID - https://orcid.org/00000002-1098-7668. 
